\title{
Faktor - Faktor yang Mempengaruhi Kinerja Pegawai Balai Besar Karantina Pertanian Tanjung Priok Jakarta
}

\author{
Safuan \\ Pasca sarjana Universitas Jayabaya \\ safuan777@gmail.com \\ Usman Putranto \\ Pasca sarjana Universitas Jayabaya \\ efriandi_up@yahoo.com

\section{Aryanda} \\ Pasca sarjana Universitas Jayabaya \\ aryandapohan@gmail.com
}

\begin{abstract}
Abstrak Penelitian ini bertujuan menguji dan menganalisis faktor-faktor yang mempengaruhi kinerja pegawai Balai Besar Karantina Pertanian Tanjung Priok. Metode sampling yang digunakan adalah proporsional random sampling. Dari populasi 150 pegawai dengan sampel sebanyak 109 pegawai. Metode analisis yang digunakan dalam penelitian ini adalah regresi linear berganda. Hasil penelitian menunjukkan budaya organisasi, motivasi kerja dan pelatihan secara bersama sama-sama (simultan) berpengaruh secara signifikan terhadap kinerja. Secara parsial budaya organisasi, dan motivasi berpengaruh signifikan positif terhadap kinerja. motivasi kerja dan pelatihan berpengaruh signifikan positif terhadap kinerja.

Kata Kunci Budaya organisasi, motivasi kerja, pelatihan dan kinerja pegawai
Abstract
This study aims to examine and analyze the factors that influence the performance of employees of the Tanjung Priok Agricultural Quarantine Center. The sampling method used is proportional random sampling. From a population of 150 employees with a sample of 109 employees. The analytical method used in this study is multiple linear regression. The results of the study show that organizational culture, work motivation and training together (simultaneously) significantly influence performance. Partially organizational culture, and motivation have a significant positive effect on performance. work motivation and training have a significant positive effect on performance.

Keywords Organizational culture, work motivation, training, employee performance

\section{I.PENDAHULUAN}

Dalam era perdagangan bebas yang ditandai dengan membanjirnya produk luar negeri yang masuk dalam wilayah Negara Republik Indonesia khusus produk pertanian. Karantina sangat berperan penting dalam mencegah hama penyakit masuk kedalam negeri (impor), demikian juga produk pertanian yang akan dikeluarkan (ekspor) keluar negeri adalah mutu / kualitas produk yang ditandai dengan sertifikat kesehatan karantina (Nely Zubaedah, dkk : 2015). Untuk itu diperlukan peran pemerintah di dalam memfasilitasi baik aturan, fasilitas, sarana dan prasarana terhadap pelaksanaan perkarantinaan di Indonesia.

Salah satu tugas pemerintah yaitu melakukan tindakan terhadap masuknya barang impor produk pertanian baik hewan dan tumbuhan dalam Wilayah Republik Indonesia maupun produk ekspor yang keluar dari wilayah Republik Indonesia khususnya di pelabuhan Tanjung Priok adalah Balai Besar Karantina Pertaninan (BBKP) Tanjung Priok selanjutnya disingkat BBKP. BBKP Tanjung Priok 
merupakan salah satu unit pelaksana teknis Badan Karantina Pertanian, Kementerian Pertanian Republik Indonesia. Yang mempunyai wilayah kerja meliputi Pelabuhan Tanjung Priok, wilayah Kerja pelabuhan Sunda Kelapa dan kantor Pos Besar Jakarta. Setiap perusahaan atau instansi mengharapkan pegawainya mempunyai prestasi atau perilaku kerja yang baik, karena dengan memiliki pegawai yang berprestasi akan memberikan sumbangan yang optimal bagi perusahaan. Pegawai berprestasi juga merupakan aset berharga (Susilo Susiawan \& Abdul Muhid:2015) sehingga terkadang perusahaan mengikat dengan berbagai cara seperti pemberian bonus, atau tunjangan yang besar dengan asumsi pegawai tersebut tidak keluar (turnover) atau mutasi dari perusahaannya.

Permasalahan mengenai kinerja merupakan permasalahan yang akan selalu dihadapi oleh pihak manajemen, karena itu manajemen perlu mengetahui faktor-faktor yang mempengaruhi kinerja karyawan. Faktor-faktor yang dapat mempengaruhi kinerja karyawan tersebut akan membuat manajemen dapat mengambil langkah yang tepat untuk berbagai kebijakan yang diperlukan, sehingga dapat meningkatkan kinerja karyawannya agar sesuai dengan harapan instansi.

Berdasarkan hasil pengamatan sementara yang terjadi pada Balai Besar Karantina Pertaninan (BBKP) Tanjung Priok, masih terdapat karyawan dengan kinerja belum optimal seperti bekerja dengan semangat ketika ada supervisor atau pengawas lapangan saja, bekerja hanya menjalankan rutinitas tanpa ada upaya untuk mencapai target yang ditentukan instansi, motivasi yang rendah dengan indikator tidak bersaing untuk mencapai prestasi kerja. Hal lain terkadang dari pihak instansi kurang memperhatikan keinginan dari para karyawan. Faktor-faktor tersebut berpengaruh terhadap pegawai dalam melaksanakan tugas-tugas yang diberikan kepadanya, sehingga hasil akhirnya adalah kinerja pegawai itu sendiri, apakah akan semakin baik atau semakin buruk.

\section{METODE PENELITIAN}

Pendekatan yang digunakan dalam penelitian ini adalah kausalitas, yaitu penelitian yang bertujuan menguraikan hubungan karakteristik dari suatu keadaan atau objek penelitian yang dilakukan melalui pengumpulan data dan analistis data kuantitatif serta pengujian statistik. Penelitian ini mempunyai tiga varibel bebas yaitu Budaya organisasi (X1), Motivasi (X2), dan Pelatihan (X3) serta satu variabel terikat yaitu Kinerja (Y). Instrumen penelitian digunakan sebagai alat ukur nilai variabel yang akan diteliti, dengan tujuan menghasilkan data kualitatif yang akurat maka setiap instrument harus mempunyai skala. Pada penelitian ini penulis menggunakan skala Likert, yang dapat menentukan indikator serta menyusun instrument yang berhubungan dengan variabel penelitian.

\section{HASIL DAN PEMBAHASAN}

Penelitian ini menggunakan angket dalam pengumpulan data. Angket atau kuesioner adalah sejumlah pertanyaan tertulis yang digunakan untuk memperoleh informasi dari responden tentang pribadi dan ruang lingkup kerjanya, atau hal-hal yang ia ketahui. (Isti Pujihastuti:2010). Tujuan digunakan angket dalam penelitian ini adalah untuk mengetahui ada atau tidaknya dan seberapa besar pengaruh budaya organisasi, motivasi, dan pelatihan terhadap kinerja pegawai Balai Besar Karantina Pertaninan (BBKP) Tanjung Priok.

Berdasarkan pengolahan data dengan menggunakan program SPSS 20.0 diperoleh hasil uji validitas, reliabilitas, uji normalitas, uji multikolinearitas, uji heteroskedastisitas, uji parsial (uji t), uji simultan (uji F), uji regresi linear berganda, uji koefisien determinasi, dan uji korelasi antar dimensi sebagai berikut:

\section{Uji Validitas}

Hasil uji validitas dari variabel budaya organisasi dengan masing-masing dimensi diperoleh nilai $r$ hitung adalah $0,547,0,569$, dan 0,495 . Jadi hasil $r$ hitung $>r$ tabel, maka data dapat diartikan valid.

Tabel 1. Hasil Uji Validitas Budaya Organisasi

\begin{tabular}{|l|c|c|c|c|}
\hline & $\begin{array}{c}\text { Scale Mean if } \\
\text { Item Deleted }\end{array}$ & $\begin{array}{c}\text { Scale Variance if } \\
\text { Item Deleted }\end{array}$ & $\begin{array}{c}\text { Corrected Item-Total } \\
\text { Correlation }\end{array}$ & $\begin{array}{c}\text { Cronbach's Alpha } \\
\text { if Item Deleted }\end{array}$ \\
\hline Budaya sebagai tapal batas & 32,31 & 10,33 & 0,547 & 0,630 \\
\hline $\begin{array}{l}\text { Budaya sebagai pemberi } \\
\text { identitas }\end{array}$ & 24,02 & 6,02 & 0,569 & 0,603 \\
\hline
\end{tabular}




\begin{tabular}{|l|l|l|l|l|}
\hline $\begin{array}{l}\text { Budaya sebagai perekat bagi } \\
\text { anggotanya }\end{array}$ & 24,57 & 6,67 & 0,495 & 0,613 \\
\hline
\end{tabular}

Sumber: Data Primer Diolah 2018

Sedangkan hasil uji validitas dari variabel motivasi dengan masing-masing dimensi diperoleh nilai $\mathrm{r}$ hitung adalah $0,354,0,592$, dan 0,612 . Jadi hasil $r$ hitung $>r$ tabel, maka data dapat diartikan valid.

Tabel 2. Hasil Uji Validitas Motivasi

\begin{tabular}{lcccc}
\hline & $\begin{array}{c}\text { Scale Mean if } \\
\text { Item Deleted }\end{array}$ & $\begin{array}{c}\text { Scale Variance } \\
\text { if Item Deleted }\end{array}$ & $\begin{array}{c}\text { Corrected Item- } \\
\text { Total } \\
\text { Correlation }\end{array}$ & $\begin{array}{c}\text { Cronbach's Alpha if } \\
\text { Item Deleted }\end{array}$ \\
\hline $\begin{array}{l}\text { Kebutuhan untuk } \\
\text { berprestasi }\end{array}$ & 28,87 & 6,93 & 0,354 & 0,633 \\
\hline $\begin{array}{l}\text { Kebutuhan untuk } \\
\text { mengaktualisasikan } \\
\text { diri }\end{array}$ & 29,18 & 5,45 & 0,592 & 0,621 \\
\hline $\begin{array}{l}\text { Kebutuhan akan } \\
\text { kekuasaan }\end{array}$ & 24,99 & 4,89 & 0,403 & 0,612 \\
\hline $\begin{array}{l}\text { Sumber: Data Primer Diolah 2018 } \\
\text { number }\end{array}$ & & &
\end{tabular}

Dan hasil uji validitas dari variabel pelatihan dengan masing-masing dimensi diperoleh nilai $r$ hitung adalah $0,273,0,295$, dan 0,347 . Jadi hasil $r$ hitung $>\mathrm{r}$ tabel, maka data dapat diartikan valid.

Tabel 3. Hasil Uji Validitas Pelatihan

\begin{tabular}{lcccc}
\hline & $\begin{array}{c}\text { Scale Mean if Item } \\
\text { Deleted }\end{array}$ & $\begin{array}{c}\text { Scale Variance if } \\
\text { Item Deleted }\end{array}$ & $\begin{array}{c}\text { Corrected Item- } \\
\text { Total } \\
\text { Correlation }\end{array}$ & $\begin{array}{c}\text { Cronbach's Alpha if } \\
\text { Item Deleted }\end{array}$ \\
\hline $\begin{array}{l}\text { Menambah } \\
\text { pengetahuan baru }\end{array}$ & 29,63 & 4,90 & 0,273 & 0,610 \\
$\begin{array}{l}\text { Mengasah } \\
\text { kemampuan dan } \\
\text { keterampilan }\end{array}$ & 25,00 & 3,54 & 0,295 & 0,648 \\
$\begin{array}{l}\text { Meningkatkan rasa } \\
\text { tanggung jawab }\end{array}$ & 21,31 & 3,29 & 0,347 & 0,605 \\
\hline Sumber: Data Primer Diolah 2018 & & &
\end{tabular}

Serta hasil uji validitas dari variabel kinerja dengan masing-masing dimensi diperoleh nilai $r$ hitung adalah $0,398,0,525$, dan 0,249 . Jadi hasil $r$ hitung $>r$ tabel, maka data dapat diartikan valid.

Tabel 4. Hasil Uji Validitas Kinerja

\begin{tabular}{lcccc}
\hline & $\begin{array}{c}\text { Scale Mean if } \\
\text { Item Deleted }\end{array}$ & $\begin{array}{c}\text { Scale Variance if } \\
\text { Item Deleted }\end{array}$ & $\begin{array}{c}\text { Corrected Item- } \\
\text { Total Correlation }\end{array}$ & $\begin{array}{c}\text { Cronbach's Alpha if } \\
\text { Item Deleted }\end{array}$ \\
\hline Kemampuan teknis & 25,59 & 3,28 & 0,398 & 0,629 \\
$\begin{array}{l}\text { Kemampuan } \\
\text { konseptual } \\
\begin{array}{l}\text { Kemampuan } \\
\text { interpersonal }\end{array}\end{array}$ & 25,38 & 2,98 & 0,525 & 0,670 \\
Sumber: Data Primer Diolah 2018 & 33,94 & 5,89 & 0,249 & 0,623 \\
\hline
\end{tabular}

Reliabilitas

Hasil perhitungan reliabilitas dari masing variabel yaitu budaya organisasi, motivasi, pelatihan dan kinerja di mana Alpha > nilai standar dapat dilihat pada tabel di bawah ini: 
Tabel 5. Hasil Perhitungan Reliabilitas

\begin{tabular}{lccc}
\hline \multicolumn{1}{c}{ Variabel } & $\begin{array}{c}\text { Cronbach's } \\
\text { Alpha }\end{array}$ & $\begin{array}{c}\text { N of } \\
\text { Items }\end{array}$ & $\begin{array}{c}\text { Nilai } \\
\text { Standar }\end{array}$ \\
\hline Budaya Organisasi & 0,767 & 10 & 0,60 \\
Motivasi Kerja & 0,700 & 10 & 0,60 \\
Pelatihan & 0,623 & 9 & 0,60 \\
Kinerja Pegawai & 0,637 & 10 & 0,60 \\
\hline Sumber: Data Primer Diolah (2018) & &
\end{tabular}

\section{Uji Normalitas}

Tabel statistik di bawah menunjukkan bahwa model regresi untuk variabel kinerja karyawan berdistribusi normal dengan Asymp. Sig. $(0,168)>0,05$; untuk variabel budaya organisasi berdistribusi normal dengan Asymp. Sig. $(0,114)>0,05$; variabel motivasi berdistribusi normal dengan Asymp. Sig. $(0,249)>0,05$; dan variabel pelatihan berdistribusi normal dengan Asymp. Sig. $(0,114)>0,05$; dengan demikian dapat dikatakan variabel budaya organisasi, motivasi, pelatihan dan kinerja dinyatakan berdistribusi normal.

Tabel 6. Uji Normalitas

One-Sample Kolmogorov-Smirnov Test

\begin{tabular}{|c|c|c|c|c|c|}
\hline & & $\begin{array}{r}\text { Budaya } \\
\text { Organisasi }\end{array}$ & $\begin{array}{r}\text { Motivasi } \\
\text { Kerja }\end{array}$ & Pelatihan & $\begin{array}{l}\text { Kinerja } \\
\text { Pegawai }\end{array}$ \\
\hline \multirow[t]{2}{*}{$\overline{\mathrm{N}}$} & & 109 & 109 & 109 & 109 \\
\hline & Mean & 40.45 & 41.52 & 37.97 & 42.45 \\
\hline Normal Parameters ${ }^{\mathrm{a}, \mathrm{b}}$ & $\begin{array}{l}\text { Std. } \\
\text { Deviation }\end{array}$ & 3.862 & 3.304 & 2.573 & 2.733 \\
\hline \multirow{3}{*}{$\begin{array}{l}\text { Most Extreme } \\
\text { Differences }\end{array}$} & Absolute & .115 & .098 & .151 & .107 \\
\hline & Positive & .063 & .066 & .105 & .107 \\
\hline & Negative & -.115 & -.098 & -.151 & -.059 \\
\hline \multicolumn{2}{|c|}{ Kolmogorov-Smirnov Z } & 1.197 & 1.020 & 1.572 & 1.113 \\
\hline \multicolumn{2}{|l|}{ Asymp. Sig. (2-tailed) } & .114 & .249 & .114 & .168 \\
\hline
\end{tabular}

a. Test distribution is Normal.

b. Calculated from data.

\section{Uji Multikolinearitas}

Nilai VIF tidak melebihi 10 sehingga dapat disimpulkan bahwa model ini tidak terkena persoalan multikolinearitas.

Tabel 7. Uji Multikolinearitas

\begin{tabular}{|c|c|c|c|c|c|c|c|c|}
\hline \multicolumn{2}{|c|}{ Model } & \multicolumn{2}{|c|}{$\begin{array}{l}\text { Unstandardize } \\
\text { d Coefficients }\end{array}$} & \multirow{2}{*}{$\begin{array}{c}\begin{array}{c}\text { Standardized } \\
\text { Coefficients }\end{array} \\
\text { Beta }\end{array}$} & \multirow[t]{2}{*}{$\mathbf{T}$} & \multirow[t]{2}{*}{ Sig. } & \multicolumn{2}{|c|}{$\begin{array}{c}\text { Collinearity } \\
\text { Statistics }\end{array}$} \\
\hline & & B & $\begin{array}{c}\text { Std. } \\
\text { Error }\end{array}$ & & & & $\begin{array}{l}\text { Toler } \\
\text { ance }\end{array}$ & VIF \\
\hline \multirow{3}{*}{1} & (Constant) & 12.650 & 3.453 & & 3.663 & .000 & & \\
\hline & BUDAYA & .229 & .057 & .323 & 4.030 & .000 & .842 & 1.188 \\
\hline & MOTIVASI & .232 & .068 & .281 & 3.418 & .001 & .804 & 1.244 \\
\hline
\end{tabular}




\begin{tabular}{|c|c|c|c|c|c|c|c|}
\hline $\begin{array}{l}\text { PELATIHA } \\
\mathrm{N}\end{array}$ & .287 & .087 & .270 & 3.318 & .001 & .816 & 1.226 \\
\hline
\end{tabular}

a. Dependent Variable: Kinerja

\section{Uji Heteroskedastisitas}

Berdasarkan grafik di atas, terlihat titik-titik menyebar secara acak, tidak membentuk sebuah pola tertentu yang jelas, serta sebaran baik di atas maupun di bawah angka 0 pada sumbu Y. Hal ini berarti tidak terjadi heteroskedastisitas pada model regresi.

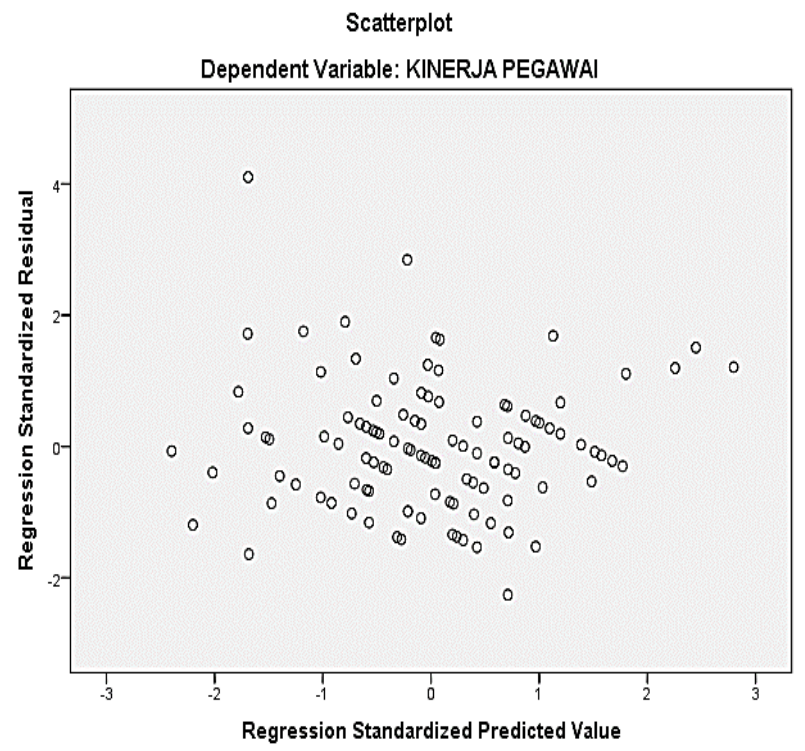

\section{Uji Linearitas}

Dasar pengambilan keputusan untuk mendeteksi kenormalan adalah jika data menyebar di sekitar garis diagonal dan mengikuti arah diagonal, maka model regresi memenuhi asumsi normalitas. Sedangkan jika data menyebar jauh dari garis diagonal atau tidak mengikuti arah diagonal, maka model regresi tidak memenuhi asumsi normalitas.

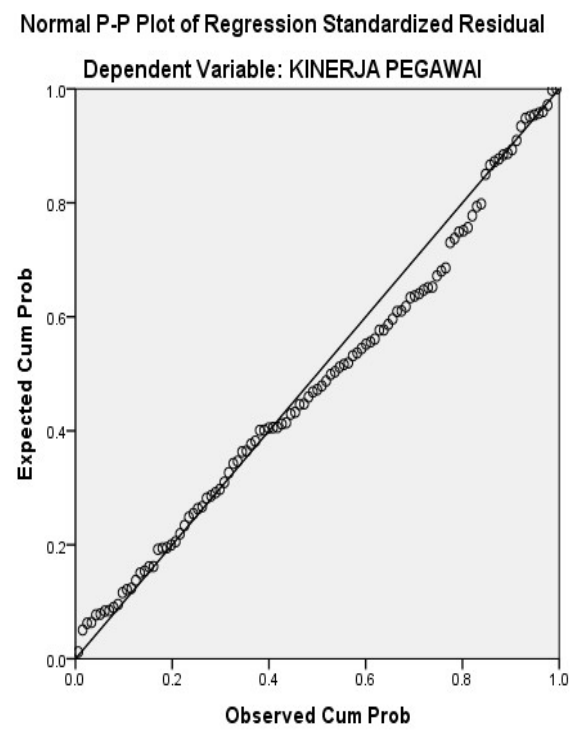




\section{Uji Regresi Simultan (Uji F)}

Berdasarkan tabel di bawah diketahui besar Fhitung $=26,529$. Jika dibandingkan dengan nilai Ftabel menggunakan probabilitas 0,5 maka diketahui nilai Ftabel $=0,05(\mathrm{k}-1) \cdot(\mathrm{n}-\mathrm{k})=0,05(\mathrm{n}-3-1) \cdot(109-4)=$ 3,89; maka dapat diketahui bahwa Fhitung > Ftabel atau 26,529 > 3,98 atau Ho ditolak dan Ha diterima.

Tabel 8. Uji Simultan

\begin{tabular}{|c|c|c|c|c|c|c|}
\hline \multicolumn{7}{|c|}{ ANOVA $^{\mathrm{a}}$} \\
\hline Model & & $\begin{array}{l}\text { Sum of } \\
\text { Squares }\end{array}$ & df & $\begin{array}{l}\text { Mean } \\
\text { Square }\end{array}$ & $\mathbf{F}$ & Sig. \\
\hline \multirow{3}{*}{1} & Regression & 347.938 & 3 & 115.979 & 26.529 & $.000^{\mathrm{b}}$ \\
\hline & Residual & 459.035 & 105 & 4.372 & & \\
\hline & Total & 806.972 & 108 & & & \\
\hline
\end{tabular}

\section{Koefesien Determinasi}

Nilai R pada tabel di bawah adalah nilai korelasi atau nilai hubungan antara budaya organisasi, motivasi dan pelatihan dengan kinerja pegawai Balai Besar Karantina Pertaninan (BBKP) Tanjung Priok, yaitu 0,657 . Sementara koefisien determinasi artinya variabel budaya organisasi, motivasi dan pelatihan memberikan kontribusi pada kinerja sebesar $43,10 \%$.

Tabel 9. Koefesien Determinasi

IV.

Model Summary

\begin{tabular}{l|r|r|r|r}
\hline Model & \multicolumn{1}{|c|}{$\mathrm{R}$} & R Square & Adjusted R Square & Std. Error of the Estimate \\
\hline 1 & $.657^{\mathrm{a}}$ & .431 & .415 & 2.091 \\
\hline
\end{tabular}

a. Predictors: (Constant), PELATIHAN, BUDAYA ORGANISASI, MOTIVASI KERJA

b. Dependent Variable: KINERJA PEGAWAI

\section{PEMBAHASAN}

\section{Pengaruh Budaya Organisasi terhadap Kinerja Pegawai}

McShane dan Von Glinow (2008:460) mendefinisikan "Organizational culture is the basic pattern of shared values and assumptions governing the way employees within an organization think about and act on problems and opportunities." Budaya organisasi adalah pola dasar nilai-nilai bersama dan asumsi yang mengatur cara karyawan dalam sebuah organisasi memikirkan dan bertindak atas masalah dan peluang.

Hasil penelitian terdahulu yang dilakukan oleh Isnanindia Septia Putri (2016) bahwa hasil pengujian hipotesis adalah budaya organisasi berpengaruh positif dan signifikan terhadap kinerja pegawai di Dinas Pendidikan dan Kebudayaan Kota Samarinda. Dengan kata lain bahwa budaya organisasi berpengaruh terhadap kinerja.

\section{Pengaruh Motivasi terhadap Kinerja Pegawai}

Motivasi merupakan penggerak yang menciptakan kegairahan kerja seseorang, agar mereka mau bekerja sama, efektif dan terintegrasi dengan segala upayanya untuk mencapai kepuasan.(Fachreza, dkk :2018). 
Ini maknanya bahwa seorang yang memiliki gaya penggerak /motivasi akan mudah untuk menjalankan tugas pekerjaanya, karena ada sesuatu yang ingin diraihnya.

Hasil penelitian terdahulu yang dilakukan oleh Daryanti,. Darti, Rohanda, Sukaesih (2013). Hasil penelitian menunjukkan bahwa pengaruh motivasi kerja intrinsik terhadap kinerja pegawai di BPAD Propinsi Bengkulu secara simultan terdapat pengaruh yang signifikan dengan ditunjukkan oleh hasil perhitungan $\mathrm{t}_{\text {hitung }}>\mathrm{t}_{\text {tabel }}$, serta dengan koefisien jalur yang positif, artinya semakin tinggi motivasi kerja intrinsik maka semakin tinggi pula kinerja pegawai; Motivasi kerja ektrinsik terhadap kinerja pegawai di BPAD Propinsi Bengkulu secara simultan terdapat pengaruh positif, artinya semakin tinggi motivasi kerja ektrinsik maka akan semakin tinggi pula kinerja pegawai, serta dengan koefisien jalur yang ditunjukkan dengan hasil perhitungan $t_{\text {hitung }}>t_{\text {tabel }}$, sehingga motivasi kerja ektrinsik berpengaruh secara signifikan terhadap kinerja pegawai.

\section{Pengaruh Pelatihan terhadap Kinerja Pegawai}

Menurut Sedarmayanti (2010:164) bahwa palatihan adalah suatu proses pendidikan jangka pendek memenfaatkan prosedur yang sistematis dan terorganisir di mana personil non manajerial mempelajari kemampuan dan pengetahuan teknis untuk tujuan tertentu. Hasil penelitian yang relevan dilakukan oleh Edi Saputra Pakpahan (2014) bahwa pengujian ini menunjukkan pendidikan berpengaruh signifikan terhadap kinerja pegawai. Untuk variabel pelatihan diperoleh nilai thitung sebesar 4,932 dengan signifikansi sebesar 0,002 . Nilai $t$ hitung $(4,932)>t$ tabel $(2,01)$ atau nilai signifikansi $(0,002<0,05)$. Pengujian ini menunjukkan bahwa variabel pelatihan berpengaruh signifikan terhadap kinerja pegawai. Dengan kata lain bahwa pelatihan berpengaruh terhadap kinerja.

\section{Pengaruh Budaya Organisasi, Motivasi dan Pelatihan terhadap Kinerja Pegawai}

Nilai koefisien determinasi (R2) yang menyatakan sumbangan bersama budaya organisasi, motivasi dan pelatihan terhadap kinerja pegawai sebesar 0,0,431. Angka ini dapat diinterpretasikan bahwa 43,10\% variansi yang ada pada variabel kinerja pegawai dapat diprediksi oleh variabel budaya organisasi, motivasi dan pelatihan, sedangkan $56,90 \%$ berasal dari variabel-vaiabel bebas lainnya sebagai penentu tingginya kinerja.

Hasil Penelitian terdahulu yang dilakukan oleh Anik Herminingsih dan Kreestianawati (2016). Hasil penelitian menunjukkan bahwa pelatihan, motivasi kerja dan budaya organisasi secara simultan berpengaruh signifikan terhadap variabel kinerja pegawai. Pengaruh paling dominan ditunjukkan oleh variabel motivasi kerja. SPSS 21. Jumlah sampel yang menjadi responden sebanyak 82 pegawai dan instrumen penelitian yang digunakan berupa kuesioner terstruktur dengan skala Likert; terdiri dari 65 pernyataan yang disusun berdasarkan indikator dan dimensi yang mendukung masing-masing variabel penelitian.

Hasil penelitian menunjukkan bahwa budaya organisasi, motivasi kerja dan pelatihan berpengaruh positif dan signifikan terhadap kinerja pegawai.

\section{V.KESIMPULAN}

Budaya organisasi berpengaruh signifikan terhadap kinerja pegawai Balai Besar Karantina Pertanian Tanjung Priok dengan kontribusi sebesar 25,50\% ( $\mathrm{rly}=0,505)$; ini maknanya bahwa 25,50\% kinerja dipengaruhi variabel budaya organisasi, terutama dimensi budaya sebagai perekat bagi anggotanya, paling dominan terhadap kinerja pegawai, karena dimensi budaya sebagai perekat bagi anggotanya merupakan kebiasaan, norma atau nilai yang berlaku dalam organisasi, yang dapat mengikat para anggotanya dengan cara berkomunikasi dan merasa memiliki organisasinya.

Motivasi kerja berpengaruh signifikan terhadap kinerja pegawai Balai Besar Karantina Pertanian Tanjung Priok dengan kontribusi sebesar 24,21\% ( $\mathrm{r} 2 \mathrm{y}=0,492)$; ini maknanya bahwa $24,21 \%$ kinerja dipengaruhi variabel motivasi kerja, terutama dimensi kebutuhan akan berprestasi, paling dominan 
terhadap kinerja pegawai, karena dimensi kebutuhan akan berprestasi merupakan suatu dorongan untuk mencapai hasil maksimal dalam bekerja, dengan mengikuti berbagai workshop dan melanjutkan ke jenjang pendidikan yang lebih tinggi.

Pelatihan berpengaruh signifikan terhadap kinerja pegawai Balai Besar Karantina Pertanian Tanjung Priok dengan kontribusi sebesar 23,04\% ( $\mathrm{r} 3 \mathrm{y}=0,480)$; ini maknanya bahwa 23,04\% kinerja dipengaruhi variabel pelatihan, terutama dimensi meningkatkan rasa tanggung jawab, yang paling dominan berpengaruh terhadap kinerja. Meningkatkan rasa tanggung jawab merupakan suatu keadaan emosional yang harus dipertanggungjwabkan demi harga diri, artinya jika ia melakukan kesalahan pekerjaan harus bertanggungjawab atas pekerjaannya tersebut, dengan cara patuh terhadap organisasi dan pekerjaan selalu tepat waktu.

Budaya organisasi, motivasi kerja dan pelatihan secara bersama berpengaruh signifikan terhadap kinerja pegawai Balai Besar Karantina Pertanian Tanjung Priok dengan kontribusi sebesar 43,10\% (r123y=0,657); ini maknanya bahwa 43,10\% kinerja dipengaruhi variabel budaya organisasi, motivasi kerja dan pelatihan. Hasil uji bersama dapat disimpulkan bahwa sumbangan bersama budaya organisasi, motivasi kerja dan pelatihan bersinergi dalam memberikan kinerja terbaik untuk Balai Besar Karantina

Pertanian sesuai dengan tujuan instansi tersebut.

\section{DAFTAR PUSTAKA}

\section{Paper dalam jurnal}

Daryanti,. Darti, Rohanda, Sukaesih (2013). Pengaruh Motivasi Kerja Terhadap kinerja Pegawai di Badan Perpustakaan, Arsip dan Dokumentasi (BPAD) Propinsi Bengkulu. Jurnal Kajian Informasi \& Perpustakaan, Vol.1/No.2

Fachreza., Musnadi, Said., Abd Majid., M. Shabri.(2018). Pengaruh Motivasi Kerja, Lingkungan Kerja, Dan Budaya Organisasi Terhadap Kinerja Karyawan Dan Dampaknya Pada Kinerja Bank Aceh Syariah Di Kota Banda Aceh. Jurnal Magister Manajemen Fakultas Ekonomi dan Bisnis Unsyiah, Vol. 2, No. 1.

Herminingsih, Anik dan Kreestianawati (2016). Pengaruh Pelatihan, Motivasi Kerja Dan Budaya Organisasi Terhadap Kinerja Pegawai Negeri Sipil. Jurnal Ilmu Ekonomi dan Sosial, Vol 5, No 3.

Pakpahan, Edi Saputra. (2014). Pengaruh Pendidikan dan Pelatihan Terhadap Kinerja Pegawai (Studi pada Badan Kepegawaian Daerah Kota Malang). Jurnal Administrasi Publik (JAP), Vol 2, No 1.

Pujihastuti, Isti. (2010). Prinsip Penulisan Kuesioner Penelitian. CEFARS : Jurnal Agribisnis dan Pengembangan Wilayah,Vol. 2 No. 1.

Septia Putri, Isnanindia.(2016). Pengaruh Budaya Organisasi Terhadap Kinerja Pegawai di Dinas Pendidikan dan Kebudayaan Kota Samarinda. eJournal Administrasi Negara, Vol. 4, No. 4.

Susiawan., Susilo. Muhid., Abdul. (2015). Kepemimpinan Transformasional, Kepuasan Kerja dan Komitmen Organisasi. Persona, Jurnal Psikologi Indonesia. Vol. 4, No. 03, hal $304-313$.

Zubaedah., Nely, Buchori., Damayanti, Munif., Abdul. (2015). Keefektifan Kebijakan Pembatasan Pintu Masuk Impor Hortikultura Terhadap Aspek Perlindungan Tanaman. Risalah Kebijakan Pertanian dan Lingkungan, Vol. 2 No. 2, 144-151.

\section{Buku}

McShane, Steven L. dan Mary Ann Von Glinow. (2008) Organizational Behavior. New York : McGRAW Hill-Internasional.

Sedarmayanti. (2010). Manajemen Sumber Daya Manusia. Bandung: Refika Aditama. 